$$
y_{0}^{2 m}
$$


Distribuclón del ingreso e incidencia de la pobreza a lo largo del ajuste

Oscar Altimir

Nuevas orientaciones para la gestión pública

Eugenio Lahera

Industrias petroquímica y de máquinas herramientas:

estrategias empresariales

Daniel Chudnovsky, Andrés López y Fernando Porta

Productividad, crecimiento y exportaciones industriales de Brasil

Regis Bonelli

Maquila en el Caribe: la experiencia de Jamaica

Larry Willmore

Elasticidad-precio de las exportaciones agrícolas de Centroamérica

De la inflaclón crónica a la inflación moderada en el Ecuador

Luis I. Jácome Hidalgo

Nuevas estrategias de las empresas transnacionales en la Argentina

Bernardo Kosacoff y Gabriel Bezchinsky

Informalidad y pobreza en América Latina

Guillermo Rosenbluth

Crisis y alternativas en los procesos de regionalización

Sergio Boisier

Una perspectiva cultural de las propuestas de la CEPAL

Fernando Calderón, Martín Hopenhayn y Ernesto Ottone

La CEPAL y el neoliberalismo: entrevista a Fernando Fajnzylber

Orientaciones para los colaboradores de la Revista de la CEPAL

Publicaciones reclentes de la CEPAL 


\section{Una perspectiva cultural de las propuestas de la CEPAL}

\section{Fernando Calderón Martín Hopenhayn Ernesto Ottone}

Experto Regional en Desarrollo Social, División de Desarrollo Social de la CEPAL.

Consultor de la División de Desarrollo Social de la CEPAL.

Secretario de la Comisión Económica para América Latina y el Caribe.
En este artículo se plantea que la propuesta de la CEPAL de transformación productiva con equidad debe considerar los rasgos culturales de las sociedades de la región. El artículo examina la propuesta de la CEPAL en una perspectiva cultural, con especial consideración del vínculo entre ciudadanía, desarrollo económico y modernidad (sección II ). Analiza los procesos de internacionalización de la cultura, la relación entre identidad cultural y ciudadanía y el impacto de los procesos de internacionalización de la cultura en la región (sección III). Examina uno de los problemas más persistentes en el proyecto de modernidad en América Latina y el Caribe -la dialéctica de la negación del otro-, el cual tiene efectos decisivos en la relación entre elites y masas, así como en el patrón de integración y de exclusión que han seguido las dinámicas de desarrollo en la región (sección IV). Formula algunas reflexiones en torno al tejido intercultural que recorre la historia y la geografía de la región y que se recompone incesantemente, a través de la interacción y modificación de las diversas culturas (seccción V). $\mathrm{Y}$ por último, plantea orientaciones de política que incorporan la dimensión cultural en la agenda del desarrollo y que permiten enriquecer el carácter sistémico de la propuesta de transformación productiva con equidad (sección VI). 


\section{I}

\section{Introducción}

Estas páginas pretenden contribuir al debate y a la reflexión que la CEPAL impulsó a partir de 1990 con su propuesta de transformación productiva con equidad. Dicha propuesta requiere de un amplio consenso de los agentes y de un escenario democrático para hacerse viable. Por ende, la construcción y la extensión de una ciudadanía moderna aparece como un aspecto esencial ella, y merece un esfuerzo reflexivo y propositivo en sí mismo. Dicha ciudadanía implica, a su vez, la existencia de actores sociales con posibilidades de autodeterminación y capacidad de representar intereses y demandas, y en pleno ejercicio de sus derechos individuales y colectivos jurídicamente reconocidos. Sin ello resulta vano hablar de construcción de consenso, de sociedad integrada o de sistemas democráticos estables.

Al definir la construcción de una ciudadanía moderna en función de la capacidad de autodeterminación de los agentes del desarrollo, un tema cada vez más gravitante en nuestra región y en las otras regiones del planeta es la tensión entre la identidad cultural y la modernidad en el proceso de desarrollo. Se trata, en otros términos, de asumir el reto de conciliar las particularidades histórico-culturales de las regiones con la vocación universalista del desarrollo y la modernidad. Como veremos más adelante, dicha tensión no sólo atraviesa las demás regiones en desarrollo, sino que constituye uno de los rasgos societales más notorios de este fin de siglo. La tensión entre identidades culturales y modernidad aparece con particular fuerza en las sociedades que experimentan hoy el llamado poscomunismo, y también se hace sentir de manera preponderante en los países más industrializados.

La hipótesis que nos ha movido a llevar a cabo este trabajo es que la transformación productiva con equidad, como propuesta de desarrollo para los países de la región, no puede prescindir de los principales rasgos culturales de nuestras sociedades. Estos rasgos son: la condición de tejido intercultural como resorte de nuestra forma propia de apertura al mundo, y la superación de la dialéctica de la negación del otro como exigencia fundamental para lograr nuestra integración social y la consolidación de una cultura democrática. Sobre dicha base es posible construir una moderna ciudadanía en la cual "el sujeto será la voluntad del individuo de ser productor y no solamente consumidor de su experiencia y de su entorno social", y la modernidad, además de progreso económico, tecnológico y social, será sobre todo "exigencia de libertad y defensa contra todo lo que transforma al ser humano en instrumento o en objeto" (Touraine, 1992, p. 272).

\section{II}

\section{La transformación productiva con equidad como una perspectiva crítica de acceso}

\section{a la modernidad}

El desarrollo de la democracia en la región plantea el siguiente desafío: ¿Cómo vincular positivamente una ciudadanía definida en un sentido secular (vale decir, que privilegie la capacidad de autodeterminación de la sociedad y el intercambio racional entre sus actores), con una dinámica de modernización económica con efectos sociales incluyentes? ¿Y de qué manera la construcción de la ciudadanía se traduce en que los actores sociales recurran a sus acervos culturales para innovar desde la propia historia?

En este nuevo escenario la propuesta de transformación productiva con equidad que la CEPAL ha elaborado para América Latina, puede llegar a entenderse, en la dimensión cultural, como una perspectiva crítica de acceso a la moderni- 
dad. ${ }^{1}$ Entendemos que una perspectiva crítica privilegia los siguientes aspectos o valores de la modernidad: el respeto de la diversidad de valores y culturas; la mayor reciprocidad de derechos en la interrelación de actores heterogéneos; la apertura en la visión de mundo hacia nuevos escenarios y desafíos, y el rescate del progreso técnico como instrumento para acrecentar la comunicación e interconexión global, promover el bienestar general y permitir campos más amplios de desarrollo de potencialidades.

Tal como se ha señalado, enfrentamos una nueva situación internacional, sumamente cambiante, marcada por una profunda revolución científica y tecnológica, por la progresiva globalización de los mercados y las comunicaciones, y por una competitividad económica basada cada vez más en la incorporación y la difusión del progreso técnico. Esta situación emergente cancela cualquier sueño (o pesadilla) de desarrollo autárquico para la región, y la obliga a orientarse hacia una inserción internacional capaz de medirse con las exigencias de un escenario globalizado. Como señala Alain Touraine, "estamos todos embarcados en la modernidad, lo que es necesario saber es si lo hacemos como galeote o como viajeros con bagajes, proyectos y memorias" (Touraine, 1992, p. 236).

Por cierto, la racionalidad instrumental, la eficacia productiva, el progreso técnico y la respuesta a las aspiraciones de consumo son elementos de la modernidad sin los cuales es imposible hablar de una inserción internacional ventajosa para la región. Pero estos elementos no bastan para garantizar la incorporación de aquellos otros que plantea la transformación productiva con equidad, vale decir, un mayor nivel de cohesión social, la sustentabilidad ambiental y la existencia de sistemas democráticos estables.

Una lectura reductiva de la modernidad que no se plantee de manera integrada y complementaria los elementos de equidad, sustentabilidad y democratización, tendería a reforzar procesos de modernización incompletos, destinados a producir enormes diferencias entre elites integradas y modernas, y vastos sectores de la población marginados y fragmentados. En tal caso, estos últimos sectores serían un fermento natural para generar reacciones de antidesarrollo, repliegue sobre identidades particulares y "defensismo" cultural.

1 Nos referimos a la propuesta contenida sobre todo en tres documentos centrales que la CEPAL ha presentado en los últimos tres años (CEPAL, 1990, 1992a y 1992b).
La propuesta de transformación productiva con equidad busca vincularse, en términos culturales, a un concepto de modernidad en que se intenta trascender los límites de la racionalización instrumental, pero también quiere romper el bloque impuesto por particularismos culturales replegados sobre sí mismos. En este sentido comparte una visión crítica de la modernidad: busca conciliar la libertad individual y la racionalización modernizadora con la pertenencia comunitaria.

En esta visión de la modernidad las identidades particulares no están destinadas a contraponerse a la modernización o transformación productiva. Por el contrario, ellas pueden ser un factor importante para su construcción si logran operar como elemento de movilización consensuada y con vocación democrática.

¿Cuáles son, en consecuencia, los factores culturales que pueden cimentar la construcción de una modernidad comprendida en estos términos?

Un primer factor es el convencimiento de que una modernidad auténtica sólo puede surgir de un esfuerzo endógeno, vale decir, movilizando las energías sociales que hacen que una sociedad se sienta responsable por su acción y por los resultados de ella. Se intenta aquí romper con aquello que José Aricó llamó "el pensamiento de la queja" y que explicaba del siguiente modo: "Es el pensamiento de lo que América Latina no puede ser porque alguien nos condena a no ser. Las teorías fueron para argumentar esta especie de sueño, de una Europa que nunca se llegó a alcanzar. La teoría de la dependencia, la teoría del subdesarrollo, venían a explicarnos que el centro de nuestros males provenía de otra parte. No de nuestra capacidad de gobierno, no de nuestra capacidad de administración, no de nuestro propio desarrollo. No digo que la dependencia no exista, no digo que el subdesarrollo no exista, estoy hablando del uso ideológico y político de ese tipo de categorización. Nuestros males estaban colocados afuera" (Aricó, 1992, p. 303).

Un segundo factor lo constituye la idea de que tal esfuerzo requiere de niveles de conflicto "controlables", y de niveles altos de consenso y estabilidad. El consenso no niega la existencia de conflictos, pero plantea una lógica de resolución institucional que pasa por la negociación y el compromiso, que excluye la negación del otro y que siempre busca evitar que se imponga toda lógica de guerra. La cultura del consenso supone, pues, un cambio significativo respecto de la cultura política tradicional en la mayor parte de 
América Latina y el Caribe, pues incluye al menos tres momentos que han sido problemáticos para la cultura política en la región: el reconocimiento de la diversidad y el fortalecimiento de los actores de la sociedad civil; la generación de negociaciones con establecimiento de compromisos, y la transformación de los acuerdos y compromisos en referencias culturales compartidas.

En este contexto, la ciudadanía aparece como un valor en que debieran entroncarse tanto los imperativos de la democracia como los del desarrollo. ${ }^{2}$ Desde esta perspectiva, ciudadanía y competitividad constituyen los dos momentos de un círculo virtuoso: "Imaginar que la ciudadanía pueda tener plena vigencia sin un esfuerzo efectivo en materia de competitividad resulta, en el decenio de 1990, tan infundado como suponer que la competitividad -necesariamente de carácter sistémico- pueda sostenerse con rezagos importantes en el ámbito de la ciudadanía" (CEPAL, 1992b, p. 18). De este modo, la ciudadanía debe pensarse como una fuente de interacción positiva entre democracia y desarrollo.

Pero además la idea moderna de ciudadanía tiene connotaciones sociológicas y culturales que conviene exponer. En primer lugar, se asocia la ciudadanía moderna con los procesos de secularización individual y grupal, en virtud de los cuales: i) se constituyen actores (individuos, grupos e instituciones) que imprimen una cierta racionalidad a sus opciones y comportamientos; ii) se institucionalizan los procesos de cambio social en función de la expansión de derechos políticos y sociales, y iii) se diferencian progresivamente los roles y las instituciones conforme a funciones específicas.

En segundo lugar, la creciente interacción de distintos actores culturales y sociales supone y expresa un consenso institucionalizado sobre la base de relaciones de recíproco reconocimiento entre actores diversos. En este sentido la ciudadanía está estrechamente ligada al reconocimiento del otro como un semejante. El énfasis en la socialización y la educación en los procesos de modernización, por ejemplo, no sólo es crucial por las exigencias de aumento productivo que tal modernización implica, sino también para el fortalecimiento de la cultura democrática mediante la difusión de valores propios de la construcción ciudadana.

2 "La formulación y aplicación de estrategias y políticas económicas habrá de ocurrir en un contexto democrático, pluralista y participativo" (CEPAL, 1990, p. 15).
En tercer lugar, ya no se trataría solamente de comprender la ciudadanía como la mera satisfacción de derechos avasallados por los regímenes autoritarios, sino como la plasmación de una serie de demandas referidas a la superación de toda forma de discriminación en el mercado y en el sistema político de toma de decisiones. Se trataría del logro de una construcción institucional sólida y renovable, que permitiese el desarrollo de negociaciones entre actores e individuos de acuerdo a normas de conducta y a derechos establecidos. En suma, de una construcción institucional convergente con un desarrollo económico cada vez más incluyente.

La reciente propuesta de la CEPAL, en la que se asigna una importancia progresiva a la educación y la producción de conocimientos en la dinámica del crecimiento, coincide con el esfuerzo de compatibilizar el desarrollo económico con la construcción de una ciudadanía democrática y moderna. Según el texto ya citado de la CEPAL, "los estudios prospectivos muestran que al convertirse el conocimiento en el elemento central del nuevo paradigma productivo, la transformación educativa pasa a ser un factor fundamental para desarrollar la capacidad de innovación y la creatividad, a la vez que la integración y la solidaridad, aspectos claves tanto para el ejercicio de la moderna ciudadanía como para alcanzar altos niveles de competitividad" (CEPAL, 1992b, p. 119).

La importancia cada vez mayor del conocimiento y la educación para el desarrollo incide significativamente en la dinámica de un orden democrático, pues la base material de las democracias ya no descansa exclusivamente en un tipo de economía o de relaciones productivas, sino también en el acervo y el uso del conocimiento, de la información y de la comunicación. ¿Cómo se cruza, pues, la centralidad del conocimiento para el desarrollo en la región, con la construcción de ciudadanía y los tejidos propios de la cultura viva en América Latina y el Caribe?

Esto nos coloca en un punto esencial de nuestras preocupaciones, a saber, el lugar que ocupan las identidades culturales en la dinámica del desarrollo y en la construcción ciudadana dentro de las sociedades contemporáneas. 


\section{III}

\section{Internacionalización de la cultura y ciudadanía}

Existen fenómenos ligados a la internacionalización de la economía, la política y la cultura que fuerzan a repensar hoy la dimensión cultural de la ciudadanía tanto en sociedades posindustriales como en países en desarrollo. De no considerar cuando menos tres de estos procesos, y su carácter global, la reflexión quedaría privada de elementos decisivos.

En primer lugar, la reformulación de la ciudadanía en función de identidades culturales es un tema de presencia creciente y concomitante en todas las latitudes. En el mundo industrializado, sobre todo en Estados Unidos y Europa occidental, las migraciones internacionales aumentan la incidencia de minorías no sólo en el aspecto demográfico, sino también en un sentido sociocultural y, en consecuencia, político. En el mundo en desarrollo, el impacto de la globalización sobre las culturas endógenas tiene efectos de análoga magnitud. El caso del Islam es muy ilustrativo: no sólo muestra cómo un factor cultural impacta las relaciones económicas y políticas, sino también, inversamente, cómo en los propios países islámicos la falta de integración social de la dinámica modernizadora refuerza la integración cultural por medio de un tradicionalismo mesiánico. ${ }^{3}$ También en países asiáticos, africanos y de Europa oriental, la multiplicidad etnocultural aumenta la conflictividad social, a medida que las sociedades se abren a los mercados mundiales e incorporan valores como la libertad de expresión y de afirmación cultural, con lo cual se intensifican demandas de afirmación étnico-territorial y religiosa. El factor cultural no sólo es una variable decisiva dentro de los países, sino que impacta cada vez más en las relaciones internacionales.

Segundo, tanto las sociedades avanzadas como aquéllas en desarrollo enfrentan un problema común, a saber, que la modernización productiva, si aspira a

\footnotetext{
3 Maxime Rodinson ha hecho recientemente una reflexión bastante heterodoxa en la cual explica la extensión del fundamentalismo islámico menos como un retorno a un pasado que nunca fue tan integrista, y mucho más por el entramado de crisis y exclusión existente en esos países. Es, según Rodinson, dicha crisis y exclusión lo que ha llevado a una relectura en clave mesiánica de los textos sagrados, y a una refundación de una historia integrista como base de legitimación de los movimientos que buscan una salida radicalintegrista a la crisis. (Véase Rodinson, 1993).
}

niveles crecientes de competitividad, exige hoy la formación de un núcleo duro de inteligencia. Pero a la vez requiere, desde su propia aspiración democrática y de desarrollo nacional, que ese núcleo duro no se construya de manera elitista, sino que forme parte de un proceso de construcción protagonizado por el conjunto de la sociedad.

No parece viable una construcción democrática del desarrollo cuando el campo de negociaciones y consensos políticos se restringe a las elites. La propia delegación política de los gobernados a los gobernantes obliga a las elites tecnopolíticas, en los escenarios emergentes de la llamada "sociedad comunicacional" y "sociedad del conocimiento", a movilizar la capacidad de intervención de los ciudadanos, proveyendo los mecanismos de información, comunicación y socialización del conocimiento entre los miembros de la sociedad.

En tercer lugar, la globalización de la cultura, resultado de la industria y el mercado cultural, ha generado una serie de fenómenos que replantean los procesos de construcción nacional. Uno de los más acuciantes es la construcción de un tiempo cultural sincrónico para el conjunto de las sociedades nacionales, en el cual los hechos y decisiones en un determinado lugar afectan inmediatamente a otro, generando una simultaneidad planetaria de la información. En el plano económico, esto implica la tendencia a la disolución de economías propiamente nacionales y a la constitución de una unidad económica internacionalizada, que funcione de manera también sincrónica. Tenderían a imponerse, de este modo, políticas económicas internacionalizadas. En la misma línea, la reorganización de los escenarios culturales y los cruces constantes de las identidades exigen preguntarse de otro modo por los órdenes que sistematizan las relaciones materiales y simbólicas entre los grupos. Fenómenos especialmente importantes para varias situaciones serían la desterritorialización de identidades culturales, y la tendencia a la descentralización de las empresas transnacionales (García Canclini, 1990, pp. 288-289).

Los procesos descritos resitúan la problemática de la construcción de la ciudadanía moderna en un vértice donde la cultura es fundamental, pero a la vez 
plantea esta misma construcción en una situación de conflicto. Es claro, por ejemplo, que existe tensión entre la tradición cultural y la racionalidad instrumental que opera en las exigencias de reconversión productiva y de aumento de la competitividad internacional de las economías nacionales. Los procesos de modernización pueden capitalizar este acervo cultural preexistente, y también pueden confrontarlo. El caso japonés, por ejemplo, es muy ilustrativo de las relaciones dinámicas entre el acervo cultural y la modernización acelerada.

La modernidad propia del ciclo industrial ha sido un proceso histórico limitado, pues no ha logrado la integración plena de la sociedad como producto de su propia actividad. Pero los límites de la modernidad son diferentes según la sociedad desde donde se la vive y desde donde se la piensa. En las sociedades avanzadas de Occidente, la construcción de la ciudadanía ha podido obtener conquistas mucho más amplias que en América Latina y el Caribe. En los países islámicos, en cambio, pareciera que los fracasos en materia de integración social han reforzado el desarrollo de un neocomunitarismo antimoderno. En el Sudeste asiático y en el Japón la modernización ha tenido un origen elitario, pero ha resultado más incluyente en lo social que en nuestra región, y ha contado con mayor legitimidad cultural. No obstante, en tales regiones la modernización exhibe importantes rezagos en los planos de la ciudadanía y del reconocimiento de diversidades culturales ajenas a las nacionalidades dominantes.

Un fenómeno de singular importancia en los nuevos procesos de internacionalización de la cultura y de la política lo constituye la generación de una serie de "culturas antimodernas"en buena parte de los países en desarrollo. También pueden observarse, empero, rasgos fundamentalistas en las sociedades industrializadas. La comprensión de estos fenomenos nos parece esencial para plantear, desde y para América Latina y el Caribe, las formas que hoy deben asumir las dinámicas de la modernidad y la universalidad en nuestra región. Este panorama conflictivo que atraviesa las diferentes regiones del planeta relativiza las expectativas optimistas que identificaron el fin de la guerra fría con una extensión generalizada y rápida de la modernidad y del sistema democrático. Actualmente presenciamos una complejidad aún mayor de la relación entre modernidad e identidad cultural, o entre universalidad "moderna" y particularismos regionales.

Los diversos conflictos nacionales o internacio- nales que actualmente desgarran una buena parte del mundo en desarrollo -esa suerte de sexto continente que ha surgido con el poscomunismo y donde en menos de tres años han aparecido 17 nuevos Estados (Ramonet, 1993), comparten un patrón: el intento de reforzar, refundar o fundar construcciones "identitarias" antimodernas. Estas construcciones responden a una profunda decepción con los procesos de modernización; tales procesos son vistos por un sector importante, e incluso mayoritario de la población, como inducidos exógenamente: casi como una simple entrada en la historia del otro (Gouffenic, 1985).

Esta percepción de los procesos de modernización como procesos extraños coincide con la crisis económica de muchos países en desarrollo, y con la imposibilidad de sus Estados de responder a la expectativa de bienestar y progreso general que en algún momento despertaron, y en torno a la cual lograron una capacidad movilizadora que hoy han perdido. Tales procesos de modernización en crisis no tuvieron un mismo principio inspirador. Para ilustrar la diversidad de principios puede invocarse la inspiración nacionalista secular de la India, la socialista nacional de Argelia, la orientación conservadora prooccidental del Irán imperial, los diversos modelos de Estados-partidos africanos y los modelos comunistas del Cáucaso soviético y los Balcanes.

Sin embargo, todos ellos se nutren de las dificultades para integrarse por vía de la modernización económica y social. Todos ellos enfrentan con dificultades el desafío de construir una síntesis entre cultura tradicional y modernidad, comparten la constitución de una elite dirigente que se percibe como escindida de la sociedad, y no han logrado consagrar canales extendidos de participación democrática.

En varios países de América Latina y el Caribe puede también observarse una tensión conflictiva en la relación entre identidades culturales y democracia política, si bien en un sentido muy distinto: tensión entre la voluntad de partidos y empresarios de institucionalizar el sistema político, por una parte, y la búsqueda de cambio cultural y social de movimientos sociales importantes —éticos, simbólico-expresivos, regionales, cooperativos, indígenas, de mujeres, de jóvenes, de obreros, de localistas urbanos y rurales-. Esto da un nuevo significado a la noción de ciudadanía, ubicándola en el cruce entre los derechos de representación política y los derechos al uso de espacios públicos para la afirmación de identidades culturales. Las demandas societales de más participación, información, comunicación o publicidad no son ajenas 
a las identidades culturales de los sectores populares o excluidos: la cultura aimara y quechua en el mundo andino, la de los "pelados" en México, o la de los marginales urbanos en Río y en Caracas.

En la interacción con las fuerzas modernizadoras, estas identidades culturales se redefinen incesantemente. Algunos de sus rasgos se pierden en los anales de la historia y otros sobreviven, modificándose en su relación con las tendencias más universales a las que se vinculan. Hoy día la exposición a ellas alcanza grados inéditos de intensidad. Los procesos de internacionalización, el acceso a la comunicación global, los cambios en el perfil educativo de la población, las nuevas relaciones generacionales y de sexo, los nuevos patrones de comportamiento y consumo: todo ello genera una tendencia incontrarrestable de diálogo conflictivo y quizás de ruptura con la tradición. En este marco se vuelve urgente entender cómo se están conformando estos nuevos cruces y cuáles son sus potencialidades para el proceso de desarrollo.

La valorización de la dimensión cultural del desarrollo puede recrear horizontes que impregnen a la política - y a las políticas - con una potencia movilizadora que convoque y seduzca a los actores sociales que se hallan más replegados sobre su propia identidad. De lo que se trata entonces es de penetrar en el entramado cultural constituido por el conjunto de representaciones y autoimágenes que circulan entre los sujetos, sobre todo aquéllos para quienes la ciudadanía es, hasta ahora, más una carencia que un hecho. Como se verá en las páginas que siguen, la dialéctica entre integrados y excluidos en nuestra región tiene una profunda raigambre cultural que refuerza este patrón de exclusión e inequidad, y le plantea dificultades muy grandes a la construcción de una ciudadanía moderna.

\section{IV}

\section{La dialéctica de la negación del otro como imposibilidad de ciudadanía}

La relación conflictiva con el otro-distinto-de-sí es esencial para ahondar en la relación entre cultura, desarrollo y ciudadanía en la región: la dialéctica de la exclusión, que en modo recurrente atraviesa el itinerario modernizador en la región desde fines del siglo pasado, y la dialéctica de la dominación entre las elites (políticas y socioeconómicas) y la sociedad toda, tiene un "suelo histórico" (no como condición suficiente, pero sí como precedente insoslayable) en la dialéctica de la negación que se remonta al fenómeno de la conquista y de la evangelización, y se prolonga por toda nuestra historia bajo la forma de la negación del otro: ese otro que puede ser mujer, indio, negro, campesino o marginal urbano.

La negación del otro presenta, en su desarrollo histórico, matices diversos. Esta construcción difiere, por ejemplo, si el encuentro cultural se realizó sobre la base de sociedades ya complejas, como las andinas o mayas, o si el encuentro se produjo frente a sociedades de menor complejidad o mayor dispersión, como las comunidades amazónicas, mapuches o caribeñas. Muy distinta ha sido, también, la dinámica de negación del otro cuando tuvo por base la migración esclava del Africa, aunque se superpone con los casos ante- riores, generando escenarios distintos, como se observa en el Brasil y buena parte del Caribe. Los matices se hacen todavía más complejos al considerar las migraciones europeas más recientes, que se entroncaron con sociedades republicanas constituidas, y tornaron más compleja la construcción de identidades nacionales, como en Argentina y Uruguay. Y como bien ha subrayado R. Adams respecto de Guatemala - lo que puede hacerse extensible a buena parte del continente- los procesos de cambio sociocultural contemplan la transición de sociedades culturalmente particulares, relativamente desestructuradas, hacia la constitución de culturas nacionales, donde el peso y la evolución siempre irregular de las relaciones socioculturales impiden que se prefiguren de manera cabal sociedades modernas integradas. 4

La dialéctica de la negación tiene muchos pliegues. Desde el lado del descubridor, el conquistador, el evangelizador, el colonizador, el criollo y finalmente el blanco, la negación parte de un doble movimiento: de una parte se diferencia al otro respecto

${ }^{4}$ Citado en José Medina Echavarría, 1980, pp. 119-120. 
de sí mismo, y en seguida se le desvaloriza y se le sitúa jerárquicamente del lado del pecado, el error o la ignorancia. En el pensamiento latinoamericano, e incluso en sus ideologías del progreso y del desarrollo, esta jerarquía se perpetúa todavía hoy como diferenciación entre el lugar del logos y el lugar del rito. El otro -indio, autóctono, no occidental- es el sujeto en que se realiza el rito: la realidad mágica, el folclore, el saber precientífico, la expresividad espontánea o el arte local. El logos - como dominio de la razón, del discurso "verdadero", de la ciencia y del desarrollo- es el dominio del "blanco", del occidental, en suma, la voz del progreso (véase Bravo, 1992). La síntesis entre "lo propio y lo universal" que se requiere para constituir una modernidad "auténtica" sigue faltando.

En términos esquemáticos se puede afirmar que el colonizador, el evangelizador y, en general, el sujeto de la cultura dominante, ha respetado a las culturas oprimidas sus prácticas de producción y reproducción: sistemas de cultivos, organización comunitaria, estrategias de supervivencia. En ello se ha podido ver que la racionalidad productiva autóctona no ha estado necesariamente reñida con la racionalidad instrumental exógena. 5 Pero la cultura dominante se ha resistido, en cambio, a reconocer que en la historia también se han dado formas concretas de enriquecimiento mutuo entre los dominios del rito y del logos. Olvida que el otro constituye no sólo una presencia mayoritaria en regiones como el Caribe o el mundo andino, sino que además ha sido y es una presencia insoslayable en las más diversas manifestaciones de la cultura y la sociedad.

La negación del otro por las elites políticas y económicas tiene, asimismo, otras caras contrapuestas y pendulares. Por un lado, el otro es el extranjero, y la cultura política latinoamericana, en sus versiones más tradicionalistas y autoritarias, ha exhibido con frecuencia resistencia al otro-extranjero: aquello que amenaza nuestra identidad desde fuera, y corroe la nación como un virus que se introduce desde la frontera. En el extremo opuesto, el propio criollo latinoamericano ha negado al otro de adentro (indio, mestizo, etc.) identificándose de manera acrítica y emula-

\footnotetext{
${ }^{5}$ Los análisis de John Murra acerca de la racionalidad productiva andina, su organización multicíclica en varios pisos ecológicos, y su vinculación a procesos de distribución macrorregionales y no mercantiles, muestran la existencia, en la cultura andina, de un sistema altamente racionalizado de producción que pervive y se reproduce hoy día (Murra, 1975). Véase un análisis de esta problemática en Rivera Cusicanqui, 1992, pp. 83-108.
}

dora con lo no autóctono, sea europeo o norteamericano. Este juego de identificaciones y diferenciaciones ha sido muy importante y eficaz en la construcción de instituciones reales.

Desde el lado del "negado" (indio, negro, zambo, esclavo, mujer, mestizo, marginal, campesino), el proceso de negación del otro también se vive con más de una cara. Por un lado se internaliza como autonegación, es decir, como cercenamiento de la identidad propia frente a sí misma. Despojado del asidero que podía dispensarle su propia identidad cultural, y del horizonte de sentido que dicha identidad le confería a su vida, navega por una orfandad interminable en medio de un mundo en que no logra reconocerse.

El otro-oprimido aparece siempre al margen de los espacios sociales en que se formulan y deciden los grandes proyectos colectivos, y en que se asignan los recursos. Esta falta de acceso define, en importante medida, la cultura oprimida. 6 También se desarrollan, del lado de este otro-negado, estrategias de preservación de la diferencia, que se observan claramente en la música, el arte, la danza, el ritualismo y el sincretismo religioso, los sistemas de cultivo y de supervivencia, los vínculos comunitarios y las reivindicaciones de territorio y de uso de la lengua vernácula.

La negación del otro en la región se manifiesta de la manera más clara y sostenida en la discriminación de las etnias indígenas y afroamericanas. La discriminación étnica contra los negros de las culturas afroamericanas no desaparece después de abolida la esclavitud: "La visión negativa del negro como explicación esencial del calamitoso cuadro que presentaban algunas repúblicas latinoamericanas del siglo XIX se fortaleció aún más cuando al correr de los años, posteriormente a la abolición, quedó claro para el simplismo racista que los negros no constituían factor de atraso por ser esclavos, sino por negros" (Romero Fraginals (comp.), 1977, p. 49). Son escasos también los mecanismos de reconocimiento de viejas y nuevas dinámicas de raigambre indígena, y la irrupción de nuevos movimientos y movilizaciones indígenas nacen del reclamo por esta carencia. En varios países del continente los indios son la mayoría, "pero ni su lengua es la oficial, ni su cultura la dominante, ni sus

\footnotetext{
6 "Se llama cultura oprimida aquella que carece de instituciones encargadas de la producción de conocimientos y de normas o estrategias para negociar, modificar y adaptar los proyectos de sociedad de sus portadores" (Casimir, 1984, p. 67).
} 
instituciones la base de la organización estatal." No es casual que en buena parte de la región los movimientos indianistas, cada vez más intercomunicados entre sí, planteen con fuerza importantes reformas culturales, reclamando la constitución de estados pluriétnicos y plurinacionales. 7

La dialéctica de la negación del otro precede a la dialéctica de la exclusión. Las distancias socioeconómicas, en muchos países de la región, siguen acompañadas por el color de la piel o por la lengua. Las relaciones de servidumbre con el personal de servicio en los hogares de clase media o clase alta, y con los trabajadores agrícolas y fabriles, sobreviven a la supuesta vocación igualitaria de la modernidad, y son la evidencia de que dicha dinámica es, todavía, un desafío pendiente en la mayoría de nuestras sociedades.

Esta negación/exclusión del otro entraña un doble rechazo al sentido más democrático e integrador que pueda pretender la modernidad. Por un lado, el rechazo por parte de quienes asumen valores universalistas de modernización, pero no los asocian con las identidades culturales específicas de la región sino que, por el contrario, subvaloran tales identidades y emulan a las elites de los países industrializados. En las antípodas de esta sensibilidad, el rechazo a la modernidad se expresa en quienes la perciben como amenaza a las raíces culturales, y se refugian en ideologías cerradas sobre sí mismas, que resisten los cambios y la apertura hacia el intercambio global. Así, la mirada de los primeros, que niega hacia adentro, se complementa y refuerza con esta mirada esencialista que niega hacia afuera. En ambos casos se exhibe una fuerte resistencia a rasgos propiamente modernos, vale decir, a las dinámicas sociales, las tensiones interculturales y la incertidumbre que caracterizan los procesos de la modernidad. Esta resistencia suele fundarse en valores rígidos que con frecuencia se materializan en una cultura política conspirativa y poco democrática.

La comprensión cultural nos provee aquí no sólo de una explicación de los orígenes de la exclusión, sino también de los fantasmas que aún nos recorren. De la inicial y prolongada impermeabilidad a esta diferencia étnica y cultural surgen muchas historias, pero sobre todo truncas: integración trunca, modernización trunca, democratización trunca. Obviamente, la fisura originaria no basta para explicar el fracaso de otros tantos proyectos. Pero sin la comprensión de

7 Véase al respecto Bonfil Batalla (1981), y Albó (1991). Para el caso del afroamericanismo en el Caribe francés, véase Casimir (1992). esta diferencia - $-\mathrm{y}$ de la diferencia dentro de nosotros-, difícilmente podremos deducir de nuestra identidad un proyecto de futuro.

Mientras se impone una racionalidad cultural basada en esta dialéctica de negación del otro, se impone también la negación del vínculo social de reciprocidad: el "distinto" queda desvalorizado, satanizado, reprimido o silenciado. Esta negación de reciprocidades en derechos y en identidades hace, a su vez, que los sujetos que formulan la discriminación y la reproducen en la práctica (sean ellos conquistadores, colonizadores, evangelizadores, blancos, ricos, oligarcas, líderes políticos, empresariales o sindicales, militares, tecnócratas públicos u operadores "modernos"), se atribuyan de manera excluyente la posesión de la verdad, del buen juicio y de la razón correcta. El discriminador se convierte, así, en juez y parte del proceso discriminatorio: crea la discriminación, la reproduce y se atribuye el derecho exclusivo de decidir sobre las jerarquías establecidas por ella.

Como rasgo cultural constitutivo en la región, la negación del otro es ambigua en su desarrollo histórico concreto. Tal ambigüedad está marcada por la transformación del negador y del negado, cuya relación es compleja y ambivalente a lo largo del tiempo; la negación se vincula a rasgos de aceptación y de adopción de las características del otro como propias. Un ejemplo clásico de esta ambivalencia está dado por el rol de la Iglesia Católica en la región, que en distintas fases de la historia moderna y contemporánea ha dado bases doctrinarias sea a ideologías políticas antimodernas, elitistas y antiigualitarias, sea a ideologías modernizadoras, democráticas y tolerantes. Otra ambivalencia la encontramos, durante el siglo pasado, en la búsqueda de una institucionalidad jurídica fundada en la reiteración de constituciones francesas, inglesas y norteamericanas, al tiempo que las mayorías nacionales padecían una exclusión significativa en lo político y en lo cultural.

Esta tradición excluyente y jerárquica se alimenta con la constante violación de los derechos de las mayorías por parte de caudillos militares, al calor de las guerras civiles, en las cruzadas de exterminio de poblaciones indígenas, con la prolongación solapada de la esclavitud negra, y con el uso de mano de obra a muy bajo costo para los trabajos más duros o degradantes.

Mientras la construcción jurídica de la ciudadanía en la región ha tendido a emular constituciones concebidas en contextos socioculturales muy distintos, las dictaduras tradicionales han incurrido en recurren- 
tes violaciones de estas constituciones. Los tejidos sociales propios del régimen de la hacienda, de la plantación o de los enclaves mineros, junto a la persistencia de relaciones familiares tradicionales de tipo patriarcal, han permitido la disociación ciudadana a la que hacemos referencia, y esta disociación no se ha superado plenamente con la transición desde sociedades oligárquicas hacia estructuras productivas más modernas.

En este sentido la transición hacia la modernidad tiene todavía un largo camino por recorrer. En muchas sociedades de la región, especialmente en las relaciones de género y en muchos nichos de trabajo (en servicios domésticos, en las zonas rurales, è incluso en parte del empleo urbano moderno), las relaciones de servidumbre siguen reforzando la reproducción de un sistema de dominación que se desprende de esta dialéctica de la negación del otro: el otro como distinto de sí, pero también como inferior a sí. La cultura de la servidumbre y la degradación sigue sirviendo como eje cultural de reproducción de la asimetría en muchos ámbitos de actividad económica y de relación social.

Pero la historia contemporánea de la región está hecha de flujos y reflujos, y las propias derrotas en las luchas por expandir la ciudadanía forjan, a su vez, "utopías de ciudadanía" que hoy día parecen encarnarse con más fuerza en la revalorización de los sistemas democráticos. Como señalaba poéticamente José Martí, "las heridas que tenemos son las libertades que nos faltan". La región está poblada por una cultura de luchas por la ciudadanía en que ha estado muy presente, de algún modo, la lucha por la inclusión del otro en un sistema de derechos compartidos. En el siglo XX, buena parte del desarrollo y la constitución del movimiento obrero y campesino, y del movimiento femenino, se centró en la consecución de derechos ciudadanos en el plano político y en el plano social.

Los llamados regímenes nacional-populares permitieron avances significativos en materia de ciudadanía política (como el derecho al voto a los antes excluidos de él) y en el plano de la ciudadanía social (acceso a educación, salud, suelos propios y otros derechos sociales básicos). Sin embargo, la creación de complejos sistemas de intermediación, como el clientelismo burocrático, el corporativismo y la constitución de Estados de tipo prebendalista, mermaron la propia capacidad de construcción ciudadana en los proyectos nacional-populares, y tendieron también a subordinar las identidades culturales y los intereses sociales a la dinámica de un sistema político con alta concentración de poder.

Los fracasos de estos esfuerzos en la construcción de una ciudadanía democrática, y el efecto traumático que las dictaduras militares posteriores dejaron en la región, convergen hoy día en una auténtica revalorización de la democracia como régimen político y como forma de vida. Por primera vez las reglas democráticas pasan a ocupar un lugar en el sentido común de sectores de distintas posiciones políticas. Estas reglas ya no figuran, en la conciencia política de muchos, como meros instrumentos circunstanciales: se las dota de valor ético en sí mismas. Muchas de las acciones de los variados movimientos sociales en la última década se orientan a la expansión de la democracia como un sistema de derechos amplios y compartidos. Dicha reconstrucción de la democracia ha permitido reconstituir una búsqueda de ciudadanía extendida.

En este contexto se plantean también demandas de mayores derechos desde distintas colectividades culturales y regionales. Un nuevo campo de conflictos ciudadanos, donde la aceptación del otro se prefigura como un tema medular, entra en la escena de la discusión pública con mayor fuerza. La lucha de mayorías y minorías etnoculturales por una mayor presencia pública, los movimientos de mujeres y sus reivindicaciones en todos los planos, los movimientos comunitaristas y localistas, constituyen señales de que la democracia no puede prescindir hoy de una construcción ciudadana con su importante carga cultural.

Todo esto lleva, posiblemente, a un cambio de las expectativas difundidas de integración social. Tal integración no se busca tan sólo en el acceso a bienes materiales, sino que se concibe cada vez más como un equilibrio entre el acceso a los bienes materiales y el acceso más difundido a los bienes simbólicos. Junto a la demanda de vivienda, de atención en salud y de diversificación del consumo, se agrega con especial fuerza la demanda de información, de conocimientos útiles, de transparencia en las decisiones, de mejor comunicación en la empresa y en la sociedad, y de mecanismos de representatividad política y de visibilidad pública. Este acceso mayor a los bienes simbólicos se ve estimulado tanto por los actuales procesos de democratización, que abren canales de participación pública, como por el impacto cada vez más profundo de la industria cultural, que integra a la sociedad por el lado del consumo simbólico.

La asincronía entre una tendencia más lenta a la integración en los procesos socioeconómicos (promo- 
vidos por la transformación productiva y la racionalización social), y una tendencia más intensiva a ella en el nivel simbólico y cultural (por efecto de la apertura política democrática y la industria cultural), podrá constituir, en los próximos años, un importante núcleo temático en la lucha por la ciudadanía en buena parte de las sociedades de la región. Este privilegio del intercambio simbólico se verá reforzado por la llamada "sociedad del conocimiento", en la cual la difusión del conocimiento constituye un eje central para la construcción de una ciudadanía donde el otro pueda ser un par. 8

Si la sociedad del conocimiento desafía a ampliar nuestra cosmovisión y a abrir nuestra sensibilidad, esta presencia del otro debiera constituir un activo potenciable. Si en lugar de negar la identidad del otro, la reconocemos incluso como presente dentro de nosotros, nuestra cosmovisión se expande. El mundo no se nos derrumba si nos abrimos a la identidad-en-ladiferencia, sino que se enriquece con nuevos contenidos. Revertir la negación del otro y reconocer a ese otro como parte de una identidad colectiva que también nos incluye a nosotros, puede ser la vía simbólica para trasmutar la negación histórica en afirmación hacia el futuro. De más está decir que no es ésta una síntesis que adviene ni espontánea ni repentinamente, sino a través de un proceso conflictivo y poblado de obstáculos. Pero el proceso mismo es de enriquecimiento cultural y de construcción de una ciudadanía en común.

\section{$\mathrm{V}$}

\section{El tejido intercultural como fuerza}

\section{de la modernidad}

Otro elemento central que atraviesa el sustrato cultural de la región es el que aquí hemos llamado tejido intercultural, entendido como la compenetración intercultural o "asimilación activa" de la cultura de la modernidad desde el acervo histórico-cultural propio. El concepto de tejido intercultural expresa tanto la idea de permeabilidad entre culturas como la idea de coexistencia de distintas temporalidades históricas en el presente de nuestra región. América Latina y el Caribe es, en este sentido, una región con un tejido específico porque combina múltiples corrientes culturales; porque desde sus orígenes ha incorporado el sincretismo como parte de su dinámica cultural e "identitaria"; porque coexiste y se mezcla lo moderno con lo no moderno tanto en su cultura como en su economía, y porque la propia conciencia de la mayoría de los latinoamericanos está poblada de cruces lingüísticos o culturales.

8 Entiéndase aquí la difusión de conocimiento en sentido amplio, a saber: como adquisición de destrezas productivas, de capacidad crítica, de autovaloración en función del propio potencial, de conciencia de sí mismo como ciudadano, de apertura para asimilar información y valores, etc. Este corolario de las reflexiones precedentes coincide, pues, con los planteos del documento de la CEPAL (1992b), en cuanto a que la difusión de la educación y del conocimiento debe activar "sinérgicamente" tanto la competitividad como la ciudadanía, difundiendo lo que se ha dado en llamar los "códigos de modernidad".
Un equívoco profundo subyace al imaginario de la modernidad en la región. Porque si con tanta frecuencia hemos querido interpretar la modernidad como superación de todo particularismo excluyente o como una suerte de "occidentalización exhaustiva" de nuestra región, con ello hemos dado la espalda al elemento de la modernidad que más se relaciona con nosotros mismos: la capacidad para integrar dinámicamente la diversidad cultural en un orden societal compartido. Tanto el indio "puro" que ha logrado defender su identidad recreando sus raíces culturales, como el reciente migrante coreano, o el descendiente de migrante español, italiano o alemán, llevan la marca del otro - sea como oprobio, sea como impulso liberador-, por cuanto construyen día a día sus identidades específicas sobre la base de interacciones culturales con otras culturas de base occidental. En América Latina y el Caribe este concepto de mestizaje como "tejido intercultural" se ha encarnado en múltiples figuras y ha recibido distintos nombres: ladinización, cimarronería, creolismo, chenko, etc.

El sincretismo o tejido intercultural, contracara de la negación del otro, al igual que ésta no es sólo un hecho originario: es también historia presente, y si bien su fuente es el encuentro de culturas distintas - siempre renovándose, además-, se ramifica hacia todo orden de cosas. El migrante campesino que se 
bate por sobrevivir en las grandes urbes es la expresión de un sincretismo espacial; las mezclas interculturales que genera la modernidad es también otra figura del sincretismo cultural; la apertura a los mercados mundiales y la heterogeneidad estructural también tienen una connotación de tejido intercultural; e incluso la tradición populista constituye un tejido sincrético en que los rasgos de la modernidad se entremezclan con culturas políticas premodernas.

En este sentido, diversas hipótesis sobre la identidad latinoamericana merecen una consideración crítica (J. Vergara Estévez y J. I. Vergara, 1992). La primera es que las transformaciones tecnológicas que ocurren a escala global tornan obsoleta la preocupación por las identidades locales, y que si existe una identidad latinoamericana, la dinámica de la apertura y la penetración tecnológica la condenan a una progresiva disolución. Una segunda hipótesis cuestionable afirma que nuestra región se define por carencia de identidad y que el problema es, entonces, cómo ser europeos o norteamericanos cabales. En el otro extremo, las hipótesis ultraindianistas e hispanistas también son excluyentes, en la medida en que desconocen el fenómeno del tejido intercultural como la base de nuestra identidad histórica.

En contraste con estas posiciones, sean de negación o de afirmación unilateral, la tesis del sincretismo cultural cuenta con mayor fundamento histórico. Desde esta perspectiva la identidad latinoamericana debe entenderse a partir de la combinación de elementos culturales provenientes de las sociedades amerindias, europeas, africanas y otras. El encuentro de culturas habría producido una síntesis cultural que se evidencia en producciones estéticas, tales como el barroco latinoamericano del siglo XVIII, o el muralismo del presente siglo. Este tejido intercultural se expresa también en la música, los ritos, las fiestas populares, las danzas, el arte y la literatura, y permea las estrategias productivas y los mecanismos de supervivencia.

Esta identidad bajo la forma de tejido intercultural ha sido considerada desde el punto de vista tanto de sus limitaciones como de sus potencialidades. En el primer caso, se señala que dicha identidad nunca ha sido del todo constituida ni asumida. Tal es la posición, por ejemplo, de Octavio Paz (1978) y de Roger Bartra (1987). En la metáfora del axolote utilizada por Bartra, la identidad latinoamericana tendría un carácter larvario o trunco, condenada a no madurar del todo. En el segundo caso, se afirma que la identidad intercultural aparece constituyendo un núcleo cultural desde el cual podemos entrar y salir de la modernidad de manera versátil, y con el cual podríamos - si asumimos plenamente la condicion del tejido intercultural - tener un acervo desde donde contrarrestar el sesgo excesivamente instrumental o "deshistorizante" de las oleadas e ideologías modernizadoras. ${ }^{9}$

De manera que el tejido intercultural es, al mismo tiempo, nuestra forma de ser modernos y de resistir la modernidad: nuestra condición de apertura cultural al intercambio con los otros y nuestro modo de incorporar la modernidad siempre de maneras sincréticas. Es, a la vez, identidad y desidentidad, o identidad y problema de identidad. El reflejo más patente lo ofrecen las grandes metrópolis de la región: Ciudad de México, Rio de Janeiro, Caracas y Lima son grandes metáforas de esta historia hecha de mezclas.

Esto no se explica solamente como efecto del patrón peculiar de modernización de las economías nacionales. Son fenómenos en que una y otra vez se manifiesta, con toda la fuerza insubordinable de la identidad, una condición cultural sincrética. Tanto en el desarrollo larvario o desigual que define los mapas y contrastes en las ciudades, como en la nueva heterogeneidad que implica a la vez fragmentación y diversidad, y en la que se dan múltiples y precarias relaciones de pertenencia, este tejido intercultural resiste la carga homogeneizadora de la modernización.

Del mismo modo que la relación con el otro, la condición cultural mentada obliga a repensar los desafíos de la modernización y de la construcción de ciudadanía con un prisma cultural. ¿Cómo capitalizar, pues, la experiencia que tiene la región en la historia de cruce intercultural, para convertirla en una ventaja comparativa en el nuevo concierto de un mundo interconectado y globalizado?

¿Cómo hacer uso de nuestra larga historia conflictivamente sincrética para asumir con mayor riqueza este desafío que hoy enfrentan también las sociedades industrializadas, y que consiste en repensar el contenido de la ciudadanía a partir de la coexistencia progresiva de identidades étnico-culturales distintas? Asumir el tejido intercultural propio es quizás hoy día el modo más auténtico de asumirse en medio de una modernidad caracterizada por una diversidad de creciente complejidad "identitaria".

\footnotetext{
${ }^{9}$ En el primer caso se ubica García Canclini (1990) y en el segun-
} do Morandé (1984). 


\section{VI}

\section{La dimensión cultural en la propuesta de}

\section{transformación productiva con equidad}

Si se considera el itinerario de la región desde la última posguerra hasta nuestros días, se observan transformaciones profundas en todos los ámbitos, que trastocan el sentido de la modernización, de la equidad, de la ciudadanía, de los conflictos en juego y de los patrones de articulación entre el Estado y la sociedad. En este contexto, parece inconcebible una propuesta de desarrollo fundada en el rechazo de la modernidad. Se trata, más bien, de "perfilar sus contenidos de manera de hacerla compatible con la equidad en lo económico-social y con la ciudadanía en lo político e institucional" (Rosales, 1993, p. 156).

Cuando la igualdad jurídico-política se ve obstaculizada por la diversidad de culturas, se produce una fuerte disociación en la cual se hace difícil conciliar tres requisitos para una modernidad expansiva: la representación política de actores y demandas diversas en un marco institucional; la participación equilibrada y argumentativa de actores en el sistema de toma de decisiones, y una mayor equidad en los resultados del desarrollo económico. Precisamente, la experiencia de nuestra región ilustra con elocuencia esta dificultad.

Las páginas precedentes plantean, para el caso de la región, la necesidad de incorporar la dimensión cultural en el proyecto de desarrollo económico y de construcción de una ciudadanía moderna y extendida. El peso de las marcas culturales obliga a esta operación, por más que carezcamos, en principio, de herramientas para abordarla. Hay, empero, indicios emergentes que pueden remecer las resistencias históricas en esta materia, como los siguientes:

i) Procesos de institucionalización democrática que nunca antes habían abarcado una proporción tan grande de los países de la región, y que sensibilizan a grandes mayorías frente a los valores de la tolerancia, la aceptación del otro y los consensos.

ii) Experiencias sociales amplias de valorización del orden y la estabilidad, a pesar de los costos socialmente regresivos de la crisis y el ajuste economico.

iii) La expansión de una industria cultural que favorece los cruces socioculturales y da posibilidades técnicas para que los espacios públicos sean más permeables a las culturas sumergidas.

iv) La propia necesidad de incorporar los sectores excluidos por el patrón de modernización vigente a la esfera de la política y del intercambio de posiciones, para garantizar mayor gobernabilidad, estabilidad económica y continuidad institucional.

Son éstos algunos de los elementos propicios para superar la dialéctica de la negación del otro y potenciar el tejido intercultural en la construcción de ciudadanía. Estos elementos tienen que incorporarse a la actual propuesta de desarrollo de la CEPAL, por su importancia en la articulación sistémica de dicha propuesta: el desarrollo económico requiere en nuestra región, dada su historia, la construcción cultural de consensos que le garanticen continuidad y dinamismo.

Pero en la relación entre los rasgos culturales y la viabilidad de la transformación productiva también existen interrogantes y problemas serios. ¿Cómo conciliar los "agentes del desarrollo" supuestos por la propuesta de transformación productiva con equidad, con las identidades culturales reales de la región? ¿Están los agentes del desarrollo (actores económicos, sociales y políticos) culturalmente preparados para impulsar dicho proceso?

Para que la vasta gama de actores socioculturales que existe en la región incida significativamente en la construcción de un consenso para el desarrollo, es necesario superar la "mentalidad rentística" en la generación de un ethos empresarial moderno y en la conformación de una ética solidaria, y buscar mecanismos de agregación y politización de las demandas de las mayorías.

Podría establecerse un vínculo estratégico entre la aspiración de los actores a la igualdad de derechos y oportunidades, y los temas centrales de la propuesta. En esta articulación entre la demanda de derechos y reconocimientos, y la demanda de incorporación a las nuevas dinámicas del desarrollo productivo, podrá centrarse la lucha por fortalecer la importancia de los actores sociales en procesos decisorios y en los nue- 
vos rumbos de modernización. Los mecanismos de intercambio democrático, esenciales para el consenso, y los de incorporación a la modernidad, tienen que movilizar a su vez mecanismos de afirmación de identidades colectivas para hacer más visibles sus demandas y potencialidades.

Los consensos democráticos para impulsar un desarrollo sostenido requieren de fuerza cultural, vale decir, de una conciencia extendida respecto de las identidades culturales asumidas, y de la reciprocidad en materia de derechos y compromisos. Lo importante es cómo se potencia esta fuerza cultural, y qué políticas pueden impulsarla.

Es probable que esta transformación de los estigmas en potencialidades culturales requiera algo más que una política sectorial en el campo de la cultura, de la industria cultural y de la comunicación de masas. Sin duda, la posibilidad de movilizar estos medios para difundir una cultura de la tolerancia y de la síntesis intercultural tiene que aprovecharse al máximo. Pero la difusión de estos valores también tiene que ganar "porosidad" en una gama muy amplia de acciones, rutinas e instituciones que pueblan el tejido social. En este marco, la necesidad de una fuerza cultural que impulse el consenso para dar al desarrollo una orientación concordante con los lineamientos de la propuesta, y que a la vez permita incorporar a dicha orientación los valores e identidades propios de nuestras sociedades, debiera contemplar al menos cuatro condiciones de alto efecto sistémico.

En primer lugar, la educación y el conocimiento, motores de la transformación productiva con equidad, deben ser capaces de vincular la construcción de una ciudadanía moderna con la difusión de un ethos empresarial hacia el conjunto de la sociedad, todo ello adaptado a las posibilidades y perfiles culturales y económicos de cada país.

En segundo lugar, es necesario avanzar en la construcción de la ciudadanía extendida mediante políticas que, adaptadas a los diferentes contextos nacionales, promuevan una cultura institucional basada en contratos, normas de conducta y derechos crecientemente compartidos por los actores involucrados. Hay entre los agentes del desarrollo y los analistas sociales un consenso creciente en torno a la idea de que los valores culturales afectan a las instituciones, y que éstas a su vez son decisivas para el comportamiento de la economía. De ello debiera deducirse la necesidad de incorporar, desde la educación básica y de manera generalizada, tanto una relación creativa con la racionalidad instrumental y las destrezas pro- ductivas, como una socialización en valores y comportamientos que fortalezcan el sentido de la ciudadanía y de la institucionalidad jurídico-democrática. Esta socialización no se restringiría, empero, a la educación básica, sino que podría también estimularse a través de una red de instituciones de capacitación, educación vocacional y educación de adultos.

En tercer lugar, es impostergable la aplicación de una política de reconocimiento, promoción e integración de los sectores que padecen una triple exclusión: la discriminación cultural (debido a factores étnicos o a claros rezagos educativos), la exclusión socioeconómica y la marginación de los mecanismos de representación y participación políticas. Dicha política debería permear un conjunto de iniciativas de integración, tanto en el plano simbólico (mediante la participación creciente de los sectores señalados en el sistema de toma de decisiones, sobre todo en el ámbito local), como en el plano material (mediante la promoción de actividades productivas, comunitarias y de capacitación, que fortalezcan la competitividad y la organización de los sectores excluidos). A este tipo de acciones podría darse un importante respaldo político mediante la puesta en marcha de pactos nacionales para la superación de la pobreza.

En cuarto lugar, e independientemente de las orientaciones de política descritas, debe tenerse plena conciencia de que toda política cultural tendrá que integrarse y adecuarse a los cambios de las sociedades informatizadas emergentes. Por ende, la política cultural (o las políticas con impacto sistémico que atañen también a la dimensión cultural), deberá promover la máxima flexibilidad, creatividad y adaptabilidad en torno a los ejes de estas sociedades emergentes, a saber: la comunicación (vinculada a la industria cultural, el mercado cultural y los medios de comunicación); la gestión (cada vez más ligada a las redes interactivas de información), y el consumo (adecuado a las necesidades y las pautas culturales de nuestras sociedades).

Se trata, en síntesis, de asumir una visión sistémica de las relaciones entre economía y cultura: reconocer que los valores y las prácticas culturales afectan a las instituciones y al comportamiento de los agentes económicos, y que la dinámica de la economía afecta, a su vez, las posibilidades de una construcción cultural compatible y afín con los desafíos de la modernidad.

Probablemente aquí tiene algo de cierto el proverbio oriental: iniciar el camino es ya el comienzo de la meta. 


\section{Bibliografia}

Albó, J. (1991): El retorno del indio, Revista andina, $\mathrm{N}^{\circ} 2$, Lima, diciembre.

Aricó, José (1992): El difícil camino de la reforma democrática, Lo popular en América Latina ¿una visión de crisis?, Lima, Desco.

Bartra, R. (1987): La jaula de la melancolía: identidad y metamorfosis del mexicano, México, D.F., Grijalbo.

Bonfil Batalla, G. (1981): Utopía y revolución, México, D.F., Nueva Imagen.

Bravo, Germán (1992): La estructura íntima del pensamiento latinoamericano: el descubrimiento del otro, mimeo.

Casimir, J. (1984): Vigencia de la cultura oprimida, Cultura y creación intelectual en América Latina, México, D.F., Siglo XXI. (1992): The Caribbean: One and Divisible, Cuadernos de la CEPAL, $N^{\circ}$ 66, Santiago de Chile, CEPAL. Publicación de las Naciones Unidas, $\mathrm{N}^{\circ}$ de venta E.92.II.G.13.

CEPAL (1990): Transformación productiva con equidad, Santiago de Chile. Publicación de las Naciones Unidas, $\mathrm{N}^{\circ}$ de venta S.90.II.G.6.

(1992a): Equidad y transformación productiva: un enfoque integrado, LC/G. 1701 (SES. 24/3), Santiago de Chile. (1992b): Educación y conocimiento: eje de la transformación productiva con equidad, Santiago de Chile. Publicación de las Naciones Unidas, $\mathrm{N}^{\circ}$ de venta S.92.II.G.6.

García Canclini, N. (1990): Culturas híbridas: estrategias para entrar y salir de la modernidad, México, D.F., Editorial Grijalbo.
Gouffenic, A. (1985): Femmes, temps, cultures, $A$ la recherche $d u$ temps des femmes, París, ACC y Tierce.

Medina Echavarría, José (1980): Sociología latinoamericana, Costa Rica, EDUCA.

Morandé, Pedro (1984): Cultura y modernización en América Latina, Santiago de Chile, Pontificia Universidad Católica de Chile,

Murra, J. (1975): Formaciones económicas y políticas del mundo andino, Lima, IEP.

Paz, O. (1978): El laberinto de la soledad, México, D.F., Fondo de Cultura Económica.

Ramonet, I. (1993): Temps nouveaux, Le monde diplomatique, año $40, N^{\circ} 470$, mayo.

Rivera Cusicanqui, S. (1992): Sendas y senderos de la ciencia social andina, Revista Autodeterminación, $\mathrm{N}^{\circ} 10, \mathrm{La} \mathrm{Paz}$, octubre.

Rodinson, Maxime (1993): L'Islam: politique et croyance, París, Fayard.

Romero Fraginals, M: (comp.) (1977): Africa en América Latina, México, D.F., Siglo XXI/UNESCO.

Rosales, O. (1993): Equidad y transformación productiva: desafío para América Latina, Revista de economía y trabajo, año I, $N^{\circ}$ 1, Santiago de Chile, Programa de Economía del Trabajo (PET), enero- junio.

Touraine, A. (1992): Critique de la modernité, París, Fayard.

Vergara Estévez, J. y J. Iván Vergara (1992): El concepto de identidad y los debates sobre la identidad cultural latinoamericana, Cuarto Congreso Chileno de Sociología, Santiago de Chile, 28-29 de agosto. 